\title{
Bald Impfung mit Nadelpflaster statt Spritze?
}

\section{Impfungen sollen bald völlig schmerz- frei sein. Die Vakzine wird dann mit- hilfe eines Pflasters verabreicht, das mit mikroskopisch kleinen Nadeln besetzt ist.}

- Das Impfpflaster ist kleiner als ein Fünfcentstück. Für die Anwendung sind keinerlei medizinische Fachkenntnisse erforderlich. Das Pflaster wird auf die desinfizierte Haut aufgeklebt und gibt den Impfstoff in wenigen Minuten über Hunderte von Mikronadeln in die Haut ab. Diese Nadeln aus Polyvinylpyrrolidon lösen sich in der Haut auf. Das Pflaster kann nach kurzer Zeit wieder von der Haut abgezogen und entsorgt werden.

\section{Kommentar}

Die Impfung per Pflaster bietet zahlreiche Vorteile. So müssen im Falle einer Pandemie lediglich die Pflaster ausgegeben werden. In armen Ländern werden Einmalspritzen oft mehrfach verwendet und dadurch Hepatitis und HIV verbreitet. Erfolgen Impfungen per Pflaster, ist diese Infektionsquelle ausgeschaltet. Das Impfpflaster muss noch klinische Tests bestehen. Wird es eingeführt, soll es nicht teurer sein als die heutige Impfspritze.

K. MALBERG .

- S. P. Sullivan et al.

Dissolving polymer microneedle patches for influenza vaccination. Published online $18 \mathrm{July}$, 2010; Nature Medicine; doi:10.1038/nm.2182

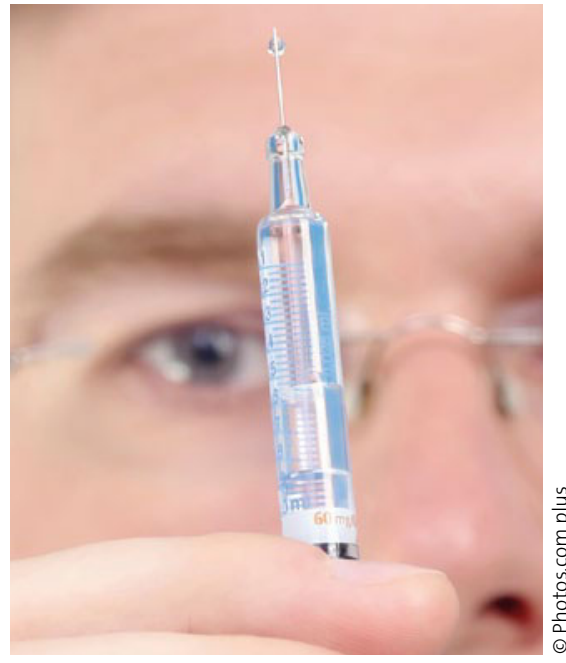

Wird die Impfspritze bald durch ein Pflaster abgelöst? 